\title{
EXPERIÊNCIAS COM EDUCAÇÃO AMBIENTAL ATRAVÉS DA EDUCAÇÃO NÃO FORMAL: O CASO DA ESCOLA ESTADUAL DE ENSINO FUNDAMENTAL DR. HONORATO DE SOUZA SANTOS
}

\author{
Letícia Paludo Vargas ${ }^{1}$, Tatiane Almeida Netto ${ }^{2}$, Letícia Fátima de Azevedo ${ }^{3}$, \\ Mirele Milani da Silva ${ }^{4}$, Clayton Hillig ${ }^{5}$ \\ ${ }^{1}$ leticiavargas@zootecnista.com.br, Mestranda do Programa de Pós-graduação em Extensão Rural da Universidade \\ Federal de Santa Maria (UFSM) \\ ${ }^{2}$ tatinetto@yahoo.com.br, Mestranda do Programa de Pós-graduação em Extensão Rural da Universidade Federal de \\ Santa Maria (UFSM) \\ ${ }^{3}$ letiazevedo@hotmail.com , Mestranda do Programa de Pós-graduação em Extensão Rural da Universidade Federal \\ de Santa Maria (UFSM) \\ ${ }^{4}$ mireleturismo@yahoo.com.br, Mestranda do Programa de Pós-graduação em Extensão Rural da Universidade \\ Federal de Santa Maria (UFSM) \\ ${ }^{5}$ hillig@smail.ufsm.br, Professor do Programa de Pós-graduação em Extensão Rural da Universidade Federal de Santa \\ Maria (UFSM)
}

http://dx.doi.org/10.5902/223613087229

\section{RESUMO}

Este trabalho vem demonstrar a relação entre educação ambiental e educação não formal e seus impactos sobre a educação básica, descrevendo a experiência do projeto Arquitetos do Saber, especificamente as oficinas ambientais envolvendo crianças da Escola Estadual de Ensino Fundamental Dr. Honorato de Souza Santos, na Localidade de Passo D'Areia, no município de Cachoeira do Sul, RS. A metodologia utilizada para o desenvolvimento desse projeto foi a pesquisa descritiva, apoiada pela Universidade Federal de Santa Maria (UFSM), inserida no Projeto Institucional UFSM/Tecnologias de Inclusão social: cidadania, educação ambiental e agroecologia, financiado pelo Edital CAPES n033/Novos Talentos 2010. As práticas de educação não formal recorrem ao conceito de simetria discursiva, e através de diálogos priorizam a inserção social do educando na ação pedagógica proporcionada através das oficinas de plantas medicinais e educação ambiental com o objetivo de socializar e construir novos conhecimentos a respeito das plantas medicinais junto à comunidade escolar. Os resultados alcançados permitiram aos educandos a tomada de consciência em relação à compreensão e aprofundamento teórico em torno dos aspectos relacionados à educação não formal, na sua relação com a educação básica trazendo subsídios para o fortalecimento das atividades educacionais envolvendo práticas de cidadania, agroecologia e educação ambiental voltada aos jovens. A educação ambiental de forma prática com crianças demonstra ser uma alternativa de aprendizagem válida, onde a troca de saberes é o elemento-chave do estudo.

Palavras-chave: educação não formal, extensão rural, meio ambiente. 


\section{ABSTRACT \\ EXPERIENCES WITH ENVIRONMENTAL EDUCATION THROUGH NO FORMAL EDUCATION: THE CASE OF SCHOOL STATE ELEMENTARY EDUCATION DR. HONORATO DE SOUZA SANTOS}

This study demonstrates the relationship between environmental education and non-formal education and its impact on basic education, describing the experience of Arquitetos do Saber Project, specifically environmental workshops involving children in the State School of Elementary Education Dr. Honorato de Souza Santos, in the Passo D'Areia, Cachoeira do Sul, RS. The methodology used for the development of this project was descriptive research, supported by the Universidade Federal de Santa Maria (UFSM), inserted into the Institutional Project UFSM / Technology Social inclusion: citizenship, environmental education and agroecology, funded by CAPES Proclamation No. 033/Novos Talents 2010. The practice of non-formal education refer to the concept of symmetry discursive, through dialogues and prioritize social inclusion of the student in the pedagogical action provided through workshops on medicinal plants and environmental education in order to socialize and build new knowledge about medicinal plants with the school community. The results allowed the students the awareness regarding the understanding and theoretical aspects around the non-formal education, in relation to basic education - bringing benefits to the strengthening of educational activities involving citizenship practices, agroecology and environmental education aimed at young people. Environmental education in a practical way with children proves to be a valid alternative learning, where knowledge exchange is the key element of the study.

Keywords: non-formal education, agricultural extension, environment.

\section{INTRODUÇÃO}

Com o objetivo de analisar a relação entre cidadania, agroecologia, educação ambiental e seus impactos sobre a educação básica, este trabalho analisa uma experiência de educação não formal envolvendo os estudantes da Escola Estadual de Ensino Fundamental Dr. Honorato de Souza Santos, situada na localidade Passo d' Areia, no município de Cachoeira do Sul, Estado do Rio Grande do Sul.

A escola participa do projeto de Extensão intitulado "Arquitetos do Saber" ${ }^{1}$, desenvolvido desde o ano de 2011, e que vem sendo realizado pelo grupo de pesquisa em Extensão Rural Aplicada do Departamento de Educação Agrícola e Extensão Rural do Centro de Ciências Rurais (CCR) da Universidade Federal de Santa Maria/RS (UFSM). O "Arquitetos do Saber" têm como principal objetivo promover a educação alicerçada nas práticas de cidadania, agroecologia e educação ambiental, visando a socialização do jovem, promovendo o diálogo e trocas culturais, além do intercâmbio entre o meio acadêmico e a educação básica. As atividades são realizadas no turno inverso das atividades curriculares da escola, sob a perspectiva da educação integral.

A educação não formal é obtida através da observação de ações do coletivo em experiências de vida compartilhadas com o grupo com o qual se interage, as quais fazem parte do aprendizado do cotidiano. Tal construção de conceitos sobre a identidade própria e do grupo, que cerca principalmente crianças e jovens, serve para construir uma consciência de agir conforme

\footnotetext{
${ }^{1}$ O projeto é financiado pela Capes/, Edital Novos Talentos e está inserido ao Projeto Institucional Tecnologias para Inclusão Social: Cidadania Educação Ambiental e Agroecologia. 
este meio ao qual é pertencente, valorizando, contribuindo e interpretando fatos e situações, criando assim possibilidades de crescimento intelectual e social (GOHN, 2010).

Nessa perspectiva, no âmbito das considerações a respeito da educação não formal, o grupo de educação ambiental, vinculado ao "Arquitetos do Saber", está desenvolvendo um trabalho com o uso de plantas medicinais, com o objetivo de demonstrar aos estudantes e seus familiares os principais usos e características das plantas, que geralmente estão disponíveis em suas próprias casas ou nas proximidades.

O uso medicinal das plantas pode ser considerado como uma abordagem do senso comum, no sentido de promover e recuperar a saúde das pessoas e, sendo esta uma prática milenar, articula cultura e saúde, em diferentes contextos históricos. Embora sejam muitos os avanços tecnológicos nos estudos fitoterápicos, a prática do uso das ervas medicinais continua sendo utilizada e difundida de forma baseada apenas na cultura popular (ALVIM et al., 2006).

A partir dessa realidade teórico-metodológica, cabe-nos questionar como as práticas desenvolvidas pelo projeto "Arquitetos do Saber" estão sendo assimiladas pelos estudantes?

A importância deste trabalho está na possibilidade de contribuir para a compreensão e aprofundamento teórico em torno dos aspectos relacionados à educação não formal, na sua relação com a educação básica - trazendo subsídios para o fortalecimento das atividades educacionais envolvendo práticas de cidadania, agroecologia e educação ambiental voltada aos jovens.

\section{METODOLOGIA}

Como recurso metodológico, procurou-se desenvolver uma pesquisa descritiva através da sistematização das práticas das oficinas ambientais e de plantas medicinais na Escola Estadual de Ensino Fundamental Dr. Honorato de Souza Santos - localidade Passo d' Areia no município de Cachoeira do Sul-RS.

As oficinas foram realizadas no primeiro semestre de 2012, com o objetivo de socializar, construir e compartilhar conhecimentos sobre plantas medicinais junto às crianças, visando também a participação dos pais dos educandos nessa dinâmica.

A metodologia utilizada nas oficinas foi coerente ao conceito de simetria discursiva, desenvolvido por Freire (1979) e pela Teoria da Ação Comunicativa desenvolvida por Habermas, destacada por Gonçalves (1999), onde as atividades ocorrem através de diálogos, interações entre os educandos, conhecimento partilhado com os mesmos e não somente direcionado a eles, priorizando a inserção do educando no processo educativo, promovendo a inserção social contextualizada com o tema de educação ambiental e plantas medicinais e a transversalidade ao currículo escolar, abordando tópicos em áreas das disciplinas de ciências.

As oficinas contaram com a participação dos estudantes, onde se buscou o estímulo à participação das crianças e dos seus pais, bem como dos professores da escola. A partir das plantas levadas pelos educandos da escola, trabalhamos o sentido e a importância das plantas medicinais, do emprego do nome científico, os usos, contra-indicações, cuidados com as dosagens, nomes populares, origem e habitat.

Para a elaboração das oficinas também utilizamos fotos de plantas medicinais, chás e dados da literatura especializada. Algumas espécies com morfologia ou nomes populares semelhantes foram trabalhadas a partir de suas principais diferenças e para isso usamos além de 
fotos, exemplares vivos, realçando as diferenças morfológicas e organolépticas (cor, cheiro, textura). Ao final de cada atividade os educandos fizeram desenhos e textos sobre as plantas estudadas. Os desenhos serão utilizados na ilustração de uma cartilha com informações sobre as plantas estudadas para uso da comunidade escolar.

\section{RESULTADOS E DISCUSSÃO}

No presente trabalho, foram analisadas e descritas as atividades desenvolvidas pelo projeto de Extensão "Arquitetos do saber" junto às crianças da Escola Estadual de Ensino Fundamental Dr. Honorato de Souza Santos, particularizando o eixo educação ambiental. Nesse sentido, Jacobi (2005), ressalta a importância da criação de novas transversalidades de saber quando se trata de educação e meio ambiente, no sentido de integrar a teoria e a prática, criando assim um novo modo de pensar, pesquisar e elaborar o conhecimento. Esta atitude deve estar presente principalmente na ação dos educadores ambientais, visando contemplar as múltiplas dimensões deste conhecimento.

Durante a realização das atividades, os educandos foram questionados a respeito do uso de plantas medicinais no seu cotidiano e, constatou-se que grande parte das crianças faz o uso das mesmas, principalmente para se fazer chás. Os educandos ressaltam que o uso dos chás é uma prática comum em suas famílias, e vem de seus antepassados, onde a mãe aprendeu com a avó e assim sucessivamente. Além disso, foram realizados trabalhos a respeito do uso das plantas medicinais, conforme mostra a Figura 1 , onde o grupo de educação ambiental realizou uma apresentação com fotos das plantas mais populares e frisou-se que a ingestão sem recomendação médica ou sem o devido conhecimento tem seus riscos, como por exemplo, a dificuldade em se estabelecer dose, posologia e, em alguns casos, a verdadeira identidade de algumas espécies, onde as crianças puderam demonstrar o seu conhecimento sobre determinada erva medicinal e sua utilização.

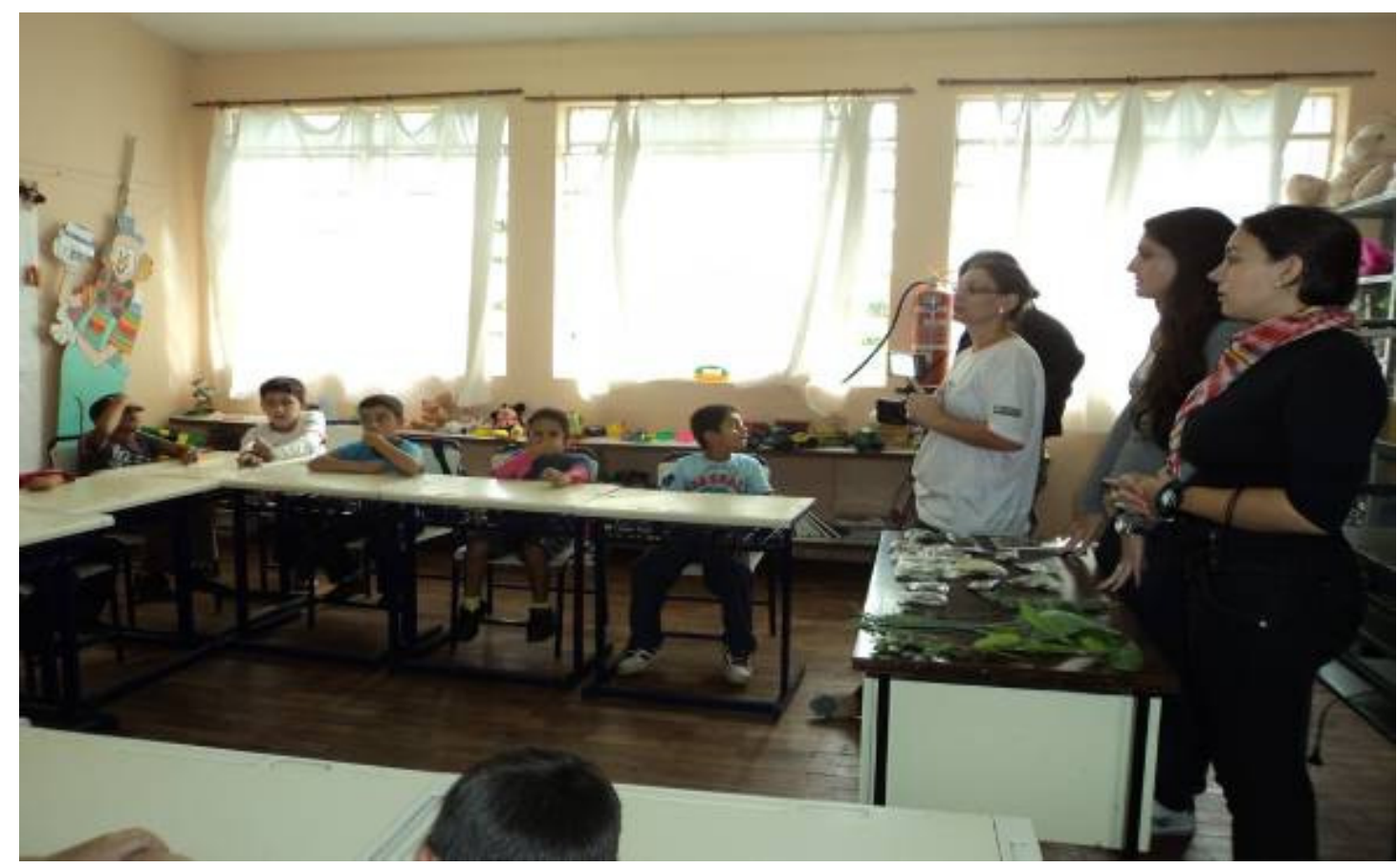

Figura 1. Atividade realizada em sala de aula: apresentação das plantas medicinais 
Pode-se observar que a maioria das crianças tinha familiaridade com as plantas, destacando dentre as mais citadas: macela (dores de estômago), erva-luíza e cidreira (calmante), boldo (dores de estômago), malva (problemas urinários e inflamações), entre outras. A partir da apresentação das plantas citadas e de outras pouco conhecidas entre as crianças, e uma breve explanação a respeito da importância das mesmas, os educandos puderam participar da aula de forma mais ativa, mostrando seu conhecimento e suas experiências para os demais.

Realizou-se como atividade prática uma visita à residência de uma das crianças, conforme mostra a Figura 2, onde a mãe cultiva diversas plantas medicinais, e os estudantes puderam ter contato direto e saber de onde elas vêm, qual o formato do pé, onde se adaptam melhor e qual a época de maior abundância. No mesmo encontro, quando os estudantes voltaram à escola, foi preparado e servido um chá com as plantas medicinais erva-luíza e cidreira, onde os mesmos tiveram a oportunidade de conhecer e ter maior contato com o objeto de estudo. Além dessas atividades, as crianças foram divididas em grupos para desenhar as plantas que tiveram contato anteriormente e descrever suas principais funções e uso na saúde humana. Esse exercício foi importante para trabalhar a capacidade de assimilação dos conteúdos administrados nas oficinas. Nessa atividade, os mesmos demonstraram interesse pelo assunto e facilidade em trabalhar em grupos.

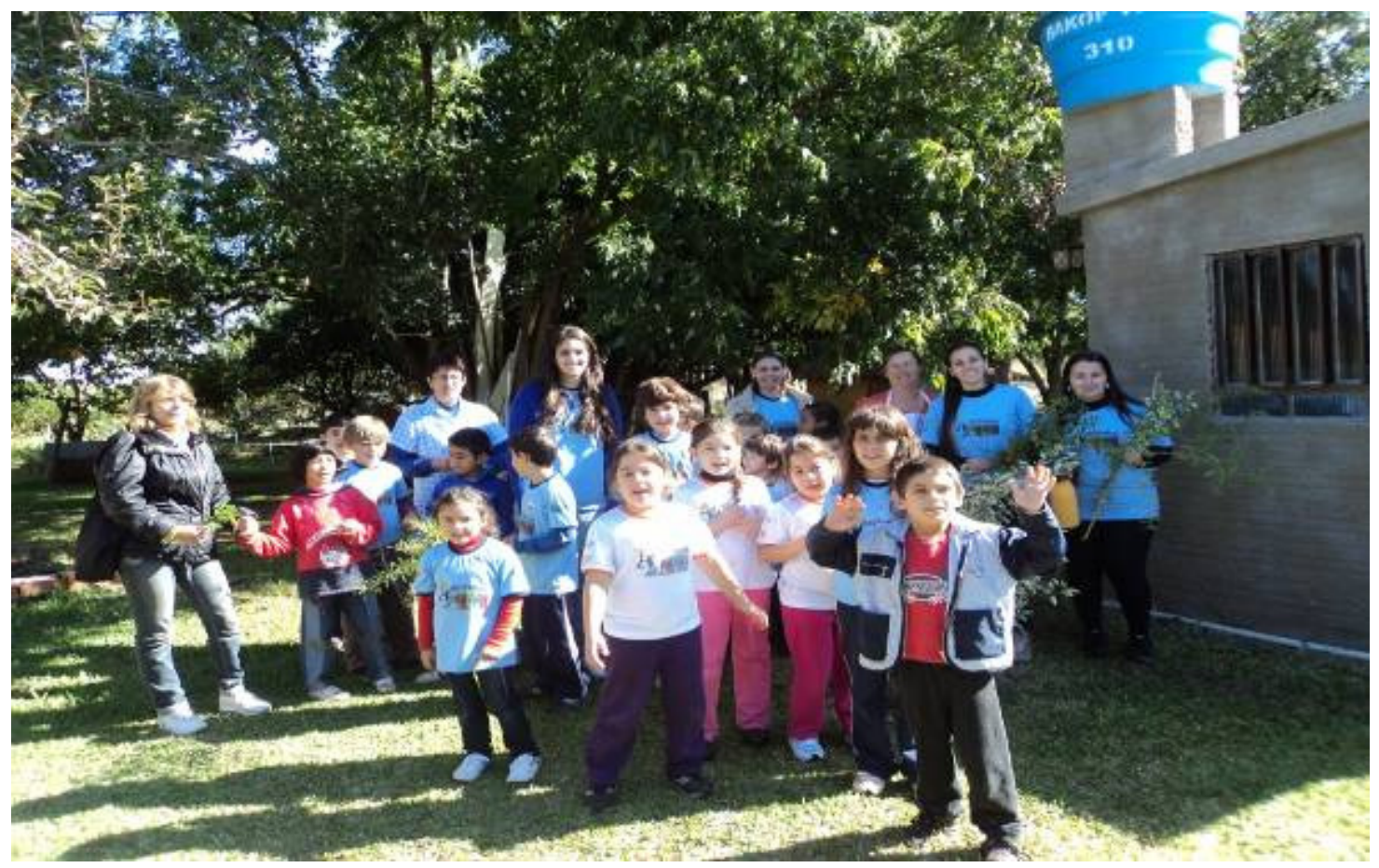

Figura 2. Atividade prática: contato direto as plantas medicinais

\section{A PRÁTICA EDUCATIVA}

Para iniciarmos a reflexão a respeito de educação, conhecimento e troca de saberes utilizamos a abordagem Freireana que nos permite refletir a respeito da educação, na qual destacamos o procedimento de aprendizagem como uma inter-relação entre comunicação e 
diálogo, onde o foco não é a transferência de saber, mas sim um "encontro de sujeitos interlocutores que buscam a significação dos significados" (FREIRE, 2006).

Entende-se como espaço educativo todo ambiente onde se promove a formação humana, e como observou Paulo Freire (1979) educação é comunicação, onde a ação comunicativa está embasada no homem concreto, que não existe senão na realidade também concreta que o condiciona. Paulo Freire ao pensar a educação e a comunicação junto, aponta o caminho para uma demanda social.

O processo-ensino-aprendizagem é visto como ato de conhecimento e transformação social, sendo pautada na perspectiva política, e possui como principal característica a utilização do saber da comunidade como matéria prima para o ensino, focando a aprendizagem a partir do conhecimento do sujeito e ensinando a partir de palavras e temas geradores do cotidiano dele.

Vinculamos a prática da ação comunicativa desenvolvida nas oficinas com a temática da educomunicação, a qual permite o diálogo e a construção de saberes e posterior emancipação social dos sujeitos envolvidos. Assim, num contexto dialético do exercício do diálogo com o outro - pessoal e institucional - propõe-se que o conceito da educomunicação seja usado para promover articulações coletivas, multiculturais e midiáticas em função do uso dos processos e ferramentas da comunicação em proveito da construção tanto dos indivíduos como das comunidades (SOARES, 2009).

A base epistemológica do projeto está associada ao conceito de educação popular, baseada em procedimentos que incentivem a participação, ou seja, um meio de veiculação e promoção para a busca da cidadania, compreendida em suas dimensões crítica e ativa. O conceito de educação popular, segundo Freire (2006) parte da realidade das práticas sociais, levando em conta o local, a região em que vive o educando e tem como objetivo primordial a inserção deste no processo educativo, de modo vivo e dinâmico, incluído numa política de desenvolvimento.

Utilizamos da educação não formal como instrumento de aprendizagem, onde Gadotti, (2005) destaca que a mesma é definida usualmente como uma oposição à educação formal, como se não pudesse aceitar a informalidade. Porém, o mesmo autor ressalta que é mais abrangente "definir a educação não formal por aquilo que ela é, pela sua especificidade e não por sua oposição à educação formal" (GADOTTI, 2005).

A educação formal é representada pelas escolas e universidades, tendo seus objetivos delineados de forma clara e específica, e nela são definidas estruturas de poder, com a fiscalização dos órgãos competentes, nesse caso, destaca-se o Ministério da Educação, em contrapartida, a educação não formal é menos hierárquica e burocrática, e nesse sentido, não precisa necessariamente seguir um sistema, ou seja, pode ter duração variável e conceder, ou não certificados, já que esse não é o objetivo principal da educação não formal (GADOTTI, 2005).

Gadotti (2005) ressalta ainda que o objetivo não é "opor a educação formal à não formal", mas sim conhecer melhor esse tipo de transmissão do conhecimento, beneficiando nesse sentido as crianças participantes desses processos de educação não formal. Na presente pesquisa, as crianças do projeto "Arquitetos do Saber" tiveram a capacidade de interagir de forma mais dinâmica com os colegas, professores e colaboradores do projeto. A evolução de todos os participantes nesse processo é nítida, pois permitiu uma acentuada troca de saberes entre professores, educandos e colaboradores.

Para Gohn (2006) a educação não formal ainda é uma área do conhecimento que se encontra em um processo de construção, e a comparação com a educação formal é quase que imediata, ou seja, para alguns pesquisadores, o tema não formal também pode ser sinônimo de informal. A autora ainda destaca que a educação formal é desenvolvida nas escolas, onde são 
abordados conteúdos previamente delimitados e a não formal ocorre através da interação dos indivíduos com a família, bairro, clube, amigos, relacionada às experiências cotidianas (GOHN, 2006).

$\mathrm{Na}$ presente pesquisa, buscou-se entrelaçar educação formal e não formal, levando assuntos cotidianos para a sala de aula. Foi feita uma abordagem desde aspectos científicos (aprendizado a respeito da origem das plantas medicinais, funções das plantas, folha, caule, raiz, etc.) com os aspectos relacionados ao conhecimento popular, onde os educandos puderam expor o que sabiam sobre plantas medicinais, que seus avós/pais ensinaram e que os mesmos faziam uso das plantas até os dias atuais.

Gohn (2006) destaca ainda as metas que a educação não formal pode atingir, destacandose o aprendizado, a socialização, o respeito mútuo, a adaptação do grupo a diferentes culturas, a construção da identidade de um grupo e o balizamento de regras éticas relativas às condutas aceitáveis pela sociedade. A autora ainda destaca os pontos fracos da educação não formal, dentre eles destacam-se: a formação específica a educadores; a definição mais clara de funções e objetivos da educação não formal; a sistematização de metodologias; a construção de metodologias para avaliação e acompanhamento do trabalho previamente realizado, o mapeamento das formas de educação não formal na auto aprendizagem, nesse caso, destacandose principalmente os jovens (GOHN, 2006).

Os trabalhos desenvolvidos nas oficinas permearam aspectos relacionados ao meio ambiente e sustentabilidade, ou seja, foi necessário mostrar aos educandos a importância da preservação ambiental, seja na escola, seja em casa. A participação dos estudantes nas rodas de discussão foi satisfatória, já que os mesmos citam exemplos da vida cotidiana, e sabem discernir entre o certo e o errado.

Uma das atividades desenvolvidas, além do trabalho com plantas medicinais, foi uma "palestra-conversa" com os estudantes, realizada no dia do meio ambiente (5 de junho), onde foram apresentados vídeos, cartazes, desenhos, jogos e possibilidade de reciclagem de materiais, relacionando todas essas atividades à importância da preservação ambiental. Nessas oficinas, destacamos a importância dos educandos repassarem os conhecimentos adquiridos a outras pessoas, questionando-os nos encontros subsequentes se eles contaram sobre as atividades desenvolvidas aos pais e irmãos e como ocorreu diálogo entre eles.

Quando relacionado à educação ambiental Jacobi (2003) destaca a interdisciplinaridade que deve ocorrer na dimensão ambiental, onde é necessário acontecer o envolvimento do conjunto de atores do universo educativo, envolvendo várias áreas do conhecimento, a comunidade universitária e a capacitação de profissionais.

É importante destacar que o Projeto Arquitetos do Saber prioriza a formação integral, onde permite a transversalidade da educação ambiental juntamente com a educação não formal e se insere nas discussões permeadas em sala de aula, pois as atividades do projeto são desenvolvidas em um turno e as curriculares em outro, permitindo que os educandos troquem o conhecimento adquirido nas atividades do projeto com a professora e os colegas, permitindo uma maior socialização de saberes.

A importância da conscientização dos indivíduos a respeito da conservação do meio em que vivem está implícita nos processos relacionados à educação ambiental, principalmente quando se trata da transformação de conduta da sociedade (CAVALCANTE, 2011). A partir da realização dos trabalhos na Escola Dr. Honorato de Souza Santos, percebe-se uma notória diferença no comportamento desses jovens, desde o início das atividades em 2011. É claramente 
visível, principalmente nas saídas a campo realizadas com os estudantes, que a mudança da conduta, tanto ambiental como social ocorreu de forma acentuada.

\section{CONCLUSÕES}

O presente estudo pôde proporcionar a análise da capacidade da educação ambiental em ampliar seu leque de possibilidades e criar estratégias para atividades educacionais a serem desenvolvidas nas mais distintas realidades, especialmente aquelas elaboradas no âmbito da educação não formal. Com efeito, através da realização da pesquisa, constatou-se que o uso de plantas medicinais é considerado uma prática comum em diversos lares da Região Sul e a explanação sobre outras formas de uso dessas plantas aliada as atividades do Projeto "Arquitetos do Saber" desenvolvidas na Escola Dr. Honorato de Souza Santos vem permitindo uma rica troca de conhecimentos entre pais, educandos e educadores.

A realização das oficinas através da educação não formal consentiu que se realizasse um processo de reflexão-ação, característico dos processos de comunicação marcados pela participação ativa dos sujeitos envolvidos e pela valorização do saber local que se inter-relaciona ao saber científico. É essa participação que propõe e capacita para a transformação social a partir do conhecimento gerado pelo ato comunicativo e a mediação.

O projeto proporcionou aos estudantes envolvidos, uma nova vivência, uma transformação não só em saberes, mas nas perspectivas de novos horizontes. A utilização de práticas como educação ambiental, cidadania e agroecologia alicerçadas na educação popular permitiu a troca de saberes, o diálogo e a aproximação entre estudantes e monitores.

Não se pode deixar de destacar, que a interação entre pais e crianças, proporcionada pelas atividades do projeto, vem contribuindo para uma maior aprendizagem de ambos, já que são levadas atividades para casa, possibilitando um desenvolvimento efetivo dos mesmos em suas atividades escolares e construção de novos conhecimentos. Dessa forma, o grupo de educação ambiental buscou unir o saber popular dos pais, avós e dos próprios estudantes da escola com os conhecimentos científicos a respeito do uso das plantas medicinais na melhoria da qualidade de vida e da saúde da população local.

O Projeto Arquitetos do Saber permite que sejam inter-relacionados aspectos relativos à educação e formação integral, destacando a cidadania; transversalidade, trabalhando paralelamente aspectos teóricos e práticos, entrelaçando didática com realidade social; e a emancipação social dos sujeitos, permitindo que os educandos tenham uma maior autonomia em suas relações com os demais. As atividades desenvolvidas no projeto, em seu caráter integral, permitem uma maior participação e entendimento dos educandos a respeito das atividades escolares e cotidianas.

As atividades desenvolvidas nos levam a constatação de que a educação ambiental de forma prática com crianças pode ser uma alternativa de aprendizagem válida, onde a troca de saberes é o elemento-chave do estudo. 


\section{REFERÊNCIAS BIBLIOGRÁFICAS}

ALVIM, N. F. et al. O uso de plantas medicinais como recurso terapêutico: das influências da formação profissional às implicações éticas e legais de sua aplicabilidade como extensão da prática de cuidar realizada pela enfermeira. Revista Latino-Americana de Enfermagem, mai/jun, 2006.

CAVALCANTE, M. B. O papel da educação ambiental na era do desenvolvimento (in)sustentável. Educação Ambiental em ação. n. 36, 2011, ISSN 1678-0701. Disponível em: <http://www.r evistaea.org/artigo.php?idartigo=1018\&class=02>. Acesso em: 05 nov 2012.

FREIRE, P. Educação como prática da liberdade. 17.ed. Rio de Janeiro: Paz e Terra, 1979.

FREIRE, P. Extensão ou comunicação?. 13. ed. São Paulo: Paz e Terra, 2006.

GADOTTI, M. A questão da educação formal/não-formal. Institut International des Droits de l'enfant (IDE). Sion, Suisse: 2005.

GOHN, M. G. Educação não-formal, participação da sociedade civil e estruturas colegiadas nas escolas. Ensaio: avaliação de políticas públicas educacionais. Rio de Janeiro, v.14, n.50, p. 27-38, jan./mar. 2006.

GOHN, M. G. Educação não-formal e o educador social: atuação no desenvolvimento de projetos sociais. São Paulo: Cortez. Coleções questões da nossa época. v.1. 2010. 103p.

GONÇALVES, M. A. S. Teoria da ação comunicativa de Habermas: Possibilidades de uma ação educativa de cunho interdisciplinar na escola. Educação \& Sociedade, ano XX, no 66, abr.1999.

JACOBI, P. R. Educação ambiental, cidadania e sustentabilidade. Cadernos de Pesquisa, n. 118, mar. 2003.

JACOBI, P. R. Educação Ambiental: o desafio da construção de um pensamento crítico, complexo e reflexivo. Educação e Pesquisa, São Paulo, v. 31, n. 2, p. 233-250, maio/ago. 2005.

SOARES, I. de O. Caminos de la educomunicación: utopías, confrontaciones, reconocimientos. Nomadas, Universidad Cental, p.194-207. Bogotá, 2009. 